Revista Monografias Ambientais - REMOA v. 15, n.1, jan-abr. 2016, p.393-403

Revista do Centro de Ciências Naturais e Exatas - UFSM, Santa Maria

\title{
PERCEPÇÃO AMBIENTAL DOS ESTUDANTES JOVENS E ADULTOS DA EDUCAÇÃO BÁSICA (PROGRAMA EJA) DE ESCOLAS PÚBLICAS MUNICIPAIS
}

\author{
Environmental perception by youth and adults students of basic education (EJA Program) of \\ public schools \\ Samuel Costa \\ Instituto Federal de Santa Catarina, campus Araranguá
}

\begin{abstract}
Resumo
A presente pesquisa objetivou avaliar a percepção ambiental dos estudantes jovens e adultos da educação básica (Programa EJA) das escolas da rede municipal da cidade de Araranguá (SC). Foi aplicado um questionário para 56 alunos do curso em questão. Para a análise referente às concepções de meio ambiente foram estabelecidas cinco categorias de concepções (romântica, utilitarista, abrangente, reducionista e sócio-ambiental). Para a análise das respostas das questões objetivas foi utilizado um padrão de contagem e para as objetivas com mais de uma resposta, foi utilizado o método de contagem/pontuação por incidência. Os resultados apontaram para a predominância de uma percepção ambiental pouco elaborada e de caráter "reducionista" e que os educandos apresentam grande interesse pelos temas ambientais. Além disso, há a disposição para participar de trabalhos e de ações de educação ambiental. Esses resultados reforçam a necessidade do envolvimento dos educandos da EJA por meio da inserção de práticas de educação ambiental no cotidiano escolar.
\end{abstract}

Palavras-chave: Meio Ambiente; Educação Ambiental; Educação de Jovens e Adultos.

Abstract

This study aimed to assess the environmental perception by youth and adults students of basic education (EJA Program) of public schools in Araranguá (SC). A questionnaire was given to 56 students of the course. For the analysis of environment conceptions, five categories of conceptions were established (romantic, utilitarian, generalizing, limited and socioenvironmental). A counting standard was used for the analysis of responses to objective questions, and, for the questions with more than one response, the method of counting/incidence score was used. The results point the predominance of an environmental perception little elaborated and of "reductionist" character. It was shown that students have great interest in environmental issues. They also show willingness to participate in activities concerning environmental education. These results also strengthen the necessity to involve the EJA students in practices to insert environmental education in their everyday life.

Keywords: Environment; Environmental Education; Youth and adults education. 


\section{Introdução}

Nas últimas décadas os problemas ambientais vêm ganhando cada vez mais notoriedade e relevância social, provavelmente, pela grande diversidade ou pela gravidade com que ocorrem. Assim, a abordagem de aspectos relacionados à temática ambiental se torna cada vez mais comum e prioritária, utilizando para isto diferentes áreas do conhecimento que oportunizem soluções técnicas e científicas, principalmente por meio da educação ambiental.

A educação ambiental se caracteriza como uma ação que objetiva sensibilizar a população sobre as questões ambientais, pois é uma ferramenta que proporciona o conhecimento sobre o meio ambiente (DIAS, 2004) e possibilita discussões que contribuem para a reflexão do indivíduo. Além disso, conforme a metodologia aplicada pode colaborar com a busca e a construção de alternativas sociais, baseadas em princípios ecológicos, éticos e de justiça (REIGOTA, 2010). A partir disto, contribui para o desenvolvimento sustentável, onde as necessidades das gerações atuais são atendidas sem comprometer as condições das futuras gerações.

No entanto, para que alcance os objetivos supracitados, a prática de educação ambiental deve ser realizada de forma contínua, de forma que construa valores, adquira conhecimentos e elucide conceitos, qualificando o indivíduo e a sociedade para a tomada de decisões (SATO; SANTOS, 2003). Mas para tanto, é necessária a resolução de problemas concretos que assolam o meio ambiente, visando à participação ativa e responsável de cada indivíduo, e da sociedade como um todo. Isto possibilita a construção de uma nova visão de mundo, que ocasione a consciência ecológica (SATO; SANTOS, 2003; DIAS, 2004; CARVALHO, 2008).

Neste processo, os indivíduos devem se entender como cidadãos ativos no processo de modificação do contexto ambiental planetário, além de não se preocuparem apenas como aspectos físicos e biológicos, mas também com os econômicos, sociais e políticos (SATO; SANTOS, 2003). No entanto, é bastante comum as pessoas enxergarem o meio ambiente como algo fora do contexto no qual estão inseridas, refletindo nas relações que mantêm em sociedade.

No contexto da educação ambientam a escola tem papel importante, devendo a temática ambiental permear todas as disciplinas de forma interdisciplinar (DIAS, 2004; REIGOTA, 2010), com enfoque em temas relativos às relações entre a humanidade e o meio natural e nas relações sociais (REIGOTA, 2010). Para tanto, deve-se analisar a realidade socioambiental na qual o aluno está inserido, de forma a modificar paradigmas na forma de perceber o meio ambiente (DIAS, 2004). Para que isto ocorra, à educação ambiental deve assumir caráter crítico, além de se apresentar como emancipatória e transformadora (BRÜGGER, 2004), em busca de novos caminhos, que passam pela participação social e pela emancipação socioambiental.

Considerando que a educação ambiental deve estar inserida nos diferentes níveis de ensino, conforme preconiza a Lei 9.795/99 (BRASIL, 1999), esta prática tem papel muito importante na educação de jovens e adultos (FRANCO; SATT, 2007; RODRIGUES et al., 2010).

Na referida modalidade de ensino a educação ambiental propícia aos educandos o entendimento da realidade na qual estão inseridos, considerando as percepções ambientais, de forma que permitam atitudes críticas em busca da mudança da situação ambiental atual. Para tanto, Franco e Satt (2007), Freitas et al. (2009) e Rodrigues et al. (2010) salientam que o educador deve utilizar temas ligados ao cotidiano dos alunos, fazendo com que percebam que estão inseridos no meio em que vivem, conduzindo-os a uma consciência ambiental crítica e cidadã. Porém, Sato e Santos (2003) e Reigota (2010) afirmam que antes da realização de práticas de educação ambiental é necessário que se conheça a percepção ambiental apresentada pelos indivíduos envolvidos, uma vez que a partir disto se pode realizar o movimento de sensibilização ambiental.

A percepção ambiental é o "processo cognitivo de apreensão de uma informação ou estímulo presente no ambiente próximo ao indivíduo [...] que efetivamente contribui para a conscientização [...] e está diretamente 
relacionada com a forma de se relacionar com as questões ambientais" (HAMMES, 2004, p.128). Assim, abrange a forma como o indivíduo enxerga, interpreta, convive e se adapta ao ambiente, ou seja, como compreende as leis que o regem, sendo decorrente de processos cognitivos, experiências, crenças, emoções, culturas e ações (SILVA; LEITE, 2008). Faggionato (2004), afirma ainda que, a percepção ambiental se caracteriza como a tomada de consciência ambiental pelo ser humano, sendo que a partir dela o indivíduo é capaz de perceber o ambiente no qual está inserido, compreender a forma como reage e responde aos acontecimentos que ocorrem no ambiente em que vive.

A partir da percepção ambiental é possível desenvolver práticas e adaptar metodologias de educação ambiental (RODRIGUES et al., 2010), por isso cada vez mais é imprescindível estudos com este enfoque. No entanto, poucos são os trabalhos que procuram conhecer a percepção ambiental de alunos da EJA (e.g. MALAFAIA; RODRIGUES, 2009; RODRIGUES et al., 2010; SANTOS; BENTO, 2010; SOUZA; TRUGILLO, 2012), sendo importante o preenchimento desta lacuna existente.

Em busca da compreensão da percepção ambiental de alunos da EJA o presente estudo foi norteado pela seguinte questão de pesquisa: Qual a percepção ambiental apresentada por alunos da educação de jovens e adultos de nível fundamental do município de Araranguá (SC)? Para tanto, foi objetivado analisar a percepção ambiental dos estudantes da educação de jovens e adultos da rede municipal de Araranguá (SC), como subsídio para as discussões de temáticas ambientais no nível de ensino em questão.

\section{Metodologia}

A presente investigação apresentou caráter quantitativo, no qual as informações obtidas foram quantificadas e computadas em números (CERVO et al., 2007; GIL, 2008). Além disso, a análise dos dados foi realizada de forma descritiva, ou seja, são descritas as características da população (GIL, 2008). Para tanto, foram utilizados procedimentos técnicos de um estudo de caso, em que há profundo estudo de um grupo, de maneira que se permita o amplo e detalhado conhecimento (YIN, 2005; ANDRÉ, 2005; GIL, 2008).

Foi realizada a pesquisa durante os anos de 2011 e 2012 nas escolas da rede pública municipal de Araranguá (SC), com as turmas de educação de jovens e adultos de nível fundamental. Participaram do estudo 56 alunos, dos 70 matriculados, selecionados de forma intencional, a partir da acessibilidade e disponibilidade para participarem da investigação. Dentre estes, a maioria $(60 \%)$ pertenciam ao gênero masculino, com idade variando dos 18 aos 50 anos.

A coleta, análise e apresentação dos dados foram realizadas com o uso de metodologia semelhante à adotada por Malafaia e Rodrigues (2009), onde foi utilizado um questionário estruturado com questões abertas e fechadas, elaboradas com base nos trabalhos de Castoldi et al. (2009) e Malafaia e Rodrigues (2009).

Para a aplicação do questionário foram seguidas as seguintes etapas: (a) apresentação do aplicador e exposição dos objetivos da pesquisa; (b) reiteração sobre o anonimato dos participantes e a confidencialidade de suas respostas; (c) informação sobre a livre deliberação de cada um em responder; e, por fim, (d) instruções específicas sobre a forma de responder aos questionários.

As respostas obtidas para as questões objetivas foram analisadas por meio de padrão de contagem, sendo os resultados apresentados em forma de gráficos, quando necessário. Para as questões objetivas com mais de uma resposta, foi utilizado o método de contagem/pontuação por incidência, sendo apresentado nos gráficos o número de vezes em que a mesma alternativa foi assinalada.

As concepções de meio ambiente foram enquadradas nas categorias expostas na tabela 1, baseadas nas proposições de Tamaio (2000), Brügger (2004) e Reigota (2010).

Tabela 1 - Categorias representativas das concepções de meio ambiente adotadas para análise, conforme a sugestão de Malafaia e Rodrigues (2009). 


\begin{tabular}{ll}
\hline Romântica & Elabora uma visão de "super-natureza", mãe natureza. Aponta a grandiosidade \\
& da natureza, sempre harmônica, enaltecida, maravilhosa, com equilíbrio e beleza \\
& estética. O homem não está inserido neste processo. Dentro desta concepção está \\
& embutida uma visão dualística, homem vs. natureza. \\
Esta postura, também dualística, interpreta a natureza como fornecedora de vida & \\
ao homem, entendendo-a como fonte de recursos para o homem. Apresenta uma & \\
leitura antropocêntrica. & \\
Abrangente & Define o meio ambiente de uma forma mais ampla e complexa. Abrange uma \\
& totalidade que inclui os aspectos naturais e os resultantes das atividades \\
& humanas, sendo assim o resultado da interação de fatores biológicos, físicos, \\
& econômicos e culturais. \\
Reducionista & Traz a ideia de que o meio ambiente refere-se estritamente aos aspectos físicos \\
& naturais, como a água, o ar, o solo, as rochas, a fauna e a flora, excluindo o ser \\
& humano e todas as suas produções. Diferentemente da categoria "romântica", não \\
proclama o enaltecimento da natureza. & \\
Desenvolve uma abordagem histórico-cultural. Essa leitura apresenta o homem e \\
a paisagem construída como elementos constitutivos da natureza. Postula uma \\
compreensão de que o homem apropria-se da natureza e que o resultado dessa \\
ação foi gerado e construído no processo histórico. Muitas vezes o homem surge \\
como destruidor e responsável pela degradação ambiental.
\end{tabular}

Foram utilizadas ainda, cinco imagens para que os educandos escolhessem a que melhor representava a ideia de meio ambiente (Figura 1), conforme sugestão de Malafaia e Rodrigues (2009). As imagens escolhidas representaram cada uma das categorias apresentadas na tabela 1.
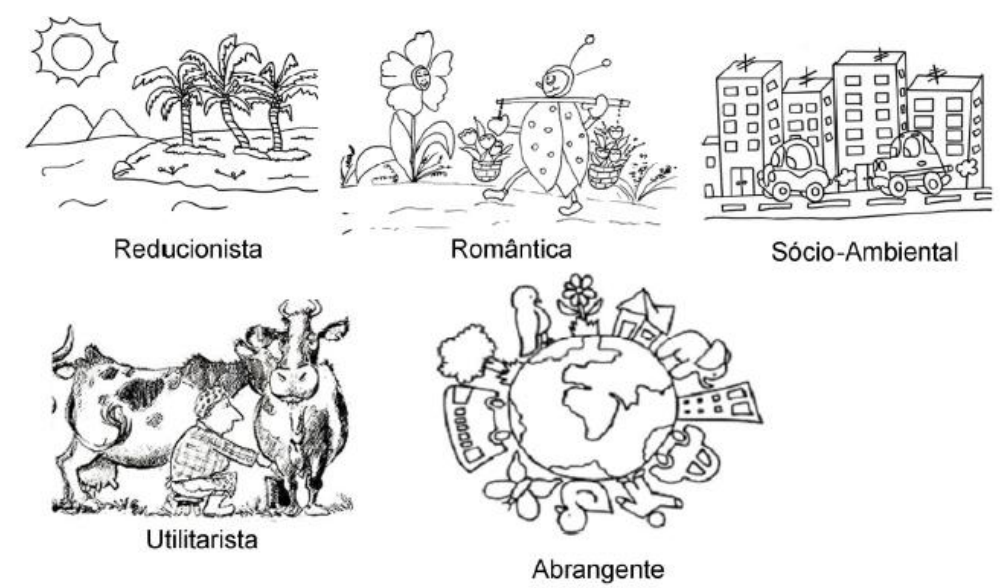

Figura 1 - Imagens apresentadas aos alunos que representam a ideia de meio ambiente.

Fonte: Malafaia e Rodrigues (2009).

\section{Resultados e discussão}

Dentre os alunos investigados a maioria (70\%) apresentou uma visão "reducionista", seguida de "abrangente" (25\%) e de "utilitarista" (5\%) de meio ambiente, quando foi pedido para que descrevesse o termo de forma discursiva. Porém, quando foi escolhida a imagem que melhor representava moo te, houve pequena modificação, onde a porcentagem de visão reducionista caiu para $60 \%$, seguida de "abrangente" (40\%).

Em estudo similar desenvolvido por Malafaia e Rodrigues (2009), com alunos da EJA de Ouro Preto (MG), foi observado que a maioria apresentou percepção reducionista, tanto na resposta discursiva, quanto na escolha da imagem. Porém, houve acréscimo de visão "abrangente" quando foi 
pedido para que escolhesse a imagem que melhor representava o meio ambiente, corroborando o ocorrido dentre os alunos investigados.

O predomínio da visão "reducionista" de meio ambiente é algo bastante comum nos diferentes níveis de ensino (COSTA et al., 2006; MOLIN et al., 2007; CASTOLDI et al., 2009). Para Malafaia e Rodrigues (2009) isto significa que não há um aprofundamento suficiente da temática ambiental, capaz de modificar a concepção de meio ambiente dos alunos, na medida em que avançam a escolaridade.

Esta situação pode estar fortemente relacionada com as visões perpetuada pelos cursos que frequentam, pois a temática ambiental, muitas vezes, não é abordada de forma interdisciplinar, e muito menos, de forma abrangente, que privilegia o caráter crítico, emancipatório e transformador. Isto pode ser um fator preponderante na predominância da percepção "reducionista" entre os alunos e a concepção errônea de não perceber o ser humano como parte integrante do meio. Este fato pode comprometer, por exemplo, práticas de educação ambiental que visem à construção de uma consciência ambiental.

A visão de meio ambiente entre o que os alunos escreveram e a imagem escolhida pode ter sido discrepante pela dificuldade em expressar de forma escrita a concepção de meio ambiente, sendo mais fácil a escolha da imagem. Além disto, Malafaia e Rodrigues (2009) destacam que a discrepância pode ter ocorrer também pela influencia da mídia, que pode induzir na escolha. A influência da mídia na concepção de meio ambiente, conforme afirma Sulaiman (2011) faz com que seja deixado de lado aquilo que está ao redor, havendo a apropriação da mensagem transmitida, em detrimento da herança cultural e cotidiana.

A diversidade de conceitos sobre meio ambiente existente entre os cientistas, que não apontam para uma consensualidade, pode ser outro fator que contribui para que a sociedade apresente uma visão baseada em representações sociais (REIGOTA, 2010), onde geralmente há o local para a instalação da percepção "reducionista". Assim, para romper com o reducionismo se faz importante que o meio ambiente seja compreendido como o "lugar determinado, onde os elementos naturais e sociais estão em relaçães dinâmicas e em interação. Estas relações implicam processos de criação cultural e tecnológica e processos históricos e sociais de transformação do meio natural e construído" (REIGOTA, 2010, p. 14).

Com a percepção 'abrangente' é possível compreender que o meio ambiente não é composto apenas de elementos naturais, como a flora, a fauna, o solo, a água e o ar, mas também por aspectos políticos, éticos, econômicos, sociais, ecológicos e culturais, dentro de um enfoque global. Para Sauvé (2005) a percepção que considera todos os aspectos listados anteriormente auxilia a formar uma visão "abrangente" de meio ambiente, contribuindo assim, para melhor compreensão dos processos educativos praticados na educação ambiental.

A forma que os estudantes investigados costumam se informar sobre os assuntos relacionados ao meio ambiente também foi questionada, sendo a escola a mais citada (42 vezes), seguida da televisão (22 vezes) e jornal (12 vezes).

Apesar de a escola ser o local mais citado, isto não necessariamente faz com que os alunos pesquisados desenvolvam uma visão "abrangente". Esta situação pode ocorrer devido ao fato de a prática de educação ambiental, quando realizada, não considerar aspectos sociais e econômicos, por exemplo, não sendo útil para o desenvolvimento da visão crítica, seja pela forma como é desenvolvida, ou por não alcançando o público alvo de forma correta.

O desenvolvimento de educação ambiental nas escolas de forma crítica, transformadora e emancipatória, conforme recomenda Brügger (2004), possibilita mudanças no pensar e no agir dos indivíduos em relação ao meio ambiente, resultando em mudanças de comportamento. Com isto, conforme salientam Marques et al. (2009), há a possibilidade de compartilhar informações e propostas capazes de sensibilizar.

Porém, as práticas de educação ambiental não devem se caracterizar como um ato isolado (SILVA et al., 2011), muito menos se como a mera transmissão de conteúdos e informações (SATO; SANTOS, 2003) mas sim, fazer parte de todo o planejamento da instituição de ensino (SILVA et al., 2011). Além de possibilitar e favorecer a formação de indivíduos dotados de responsabilidade ambiental, social e 
política, que visem à construção de uma sociedade sustentável e formação de uma consciência ambiental.

Para o desenvolvimento de consciência ambiental as práticas que envolvem as questões ambientais, realizadas junto aos alunos investigados, devem ocorrer de forma consistente, com objetivos bem claros, de forma interdisciplinar e articulada, uma vez que é nas escolas onde mais encontram informações acerca do tema. Com a aquisição de maior consciência ambiental os educandos podem agir individual e coletivamente, de modo que enfrentem problemas ambientais atuais ou que estão por vir.

Juntamente com a escola, a mídia foi o segundo veículo responsável pelas informações sobre meio ambiente para os alunos investigados. Este meio é bastante atuante na abordagem das temáticas ambientais, uma vez que a maioria da sociedade tem acesso às informações midiáticas. Porém, muitas vezes o indivíduo que escuta falar sobre meio ambiente por este meio, cujos exemplos se atem as florestas, aos animais, aos rios e aos mares, por exemplo, cria significado errôneo ou limitado para o termo, baseado em uma visão "reducionista". Desta forma, de acordo com Marques et al. (2009), cada vez que ouvir falar em meio ambiente, o relacionará a esses elementos, pois é o que guarda no subconsciente.

Apesar disto, a mídia é um veículo importante na divulgação de questões ligadas ao meio ambiente, exercendo grande influência na forma como as pessoas o percebem (SILVA et al., 2011). Por isto, em práticas de educação ambiental a mídia deve sempre ser considerada, pois tem peso considerável na divulgação e formação da percepção ambiental do público investigado.

Assim, no contexto da educação ambiental, a mídia se constitui como instrumento importante na sensibilização ambiental, uma vez que faz com que questões ambientais, como a mudança climática, o aquecimento global, por exemplo, ganhe notoriedade e relevância social. No entanto, a escola ainda possui papel crucial no processo, pois neste espaço é possível analisar a relevância e veracidade das informações veiculadas (SULAIMAN, 2011).

Foi perguntado também aos alunos com que frequência à temática ambiental é abordada em sala de aula. Todos os alunos afirmaram que o tema é abordado nas aulas, sendo que $70 \%$ entendem que é trabalhado com alta frequência (Figura 2), corroborando informações de outros estudos (e.g. CASTOLDI et al., 2009; MALAFAIA ; RODRIGUES, 2009).

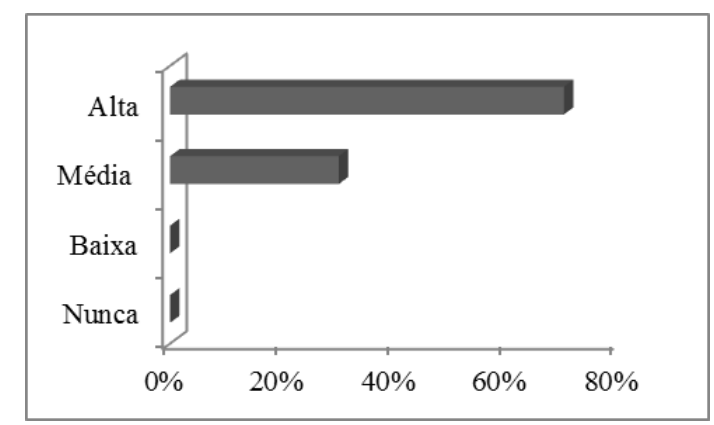

Figura 2 - Frequência com que o tema meio ambiente é trabalhado nas aulas.

Na escola a temática ambiental deve ser trabalhada em todas as disciplinas e níveis de ensino, uma vez que é considerada como tema transversal pelos Parâmetros Curriculares Nacionais (PCNs). Dentre as várias formas de trabalhar a educação ambiental, os PCNs destacam que a interdisciplinaridade é um caminho bastante promissor. Para tanto, Freitas et al. (2009) recomendam desfragmentar os conteúdos e reunir as informações dentro de um mesmo contexto, nas mais variadas disciplinas. Isto se faz importante, pois as questões ambientais não podem ser ignoradas pela escola, uma vez que a atenção ao meio ambiente vem sendo considerada urgente e importante para a sociedade (MALAFAIA; RODRIGUES, 2009).

No entanto, muitas são as dificuldades encontradas pelos professores para trabalhar temas ligados ao meio ambiente, como, por exemplo, o fato de o desenvolvimento deste tema se tornar uma carga a mais para o docente. Além disto, no âmbito escolar há certa dificuldade em diferenciar ecologia e educação ambiental, além da desmotivação causada pela pouca valorização da profissão e pelo 
desinteresse dos alunos (CASTOLDI et al., 2009), contribuindo abordagem superficial, que pode contribuir para a perpetuação da visão "reducionista".

Considerando o fato de o tema ser abordado com alta regularidade nas escolas, os professores têm papel importante como mediadores do conhecimento, pois trazem significados e concepções sobre a temática, que pode acabar interferindo ou influenciando na percepção ambiental dos alunos.

Algumas pesquisas têm sido realizadas buscando conhecer a concepção de meio ambiente de professores (e.g. BEZERRA; GONÇALVES, 2007; BEZERRA et al., 2008; FRAZÃO et al. 2010; SANTOS; BENTO, 2012) e os resultados demonstraram que a maioria apresenta uma visão "reducinonista". Para superar tal situação, faz-se importante a formação continuada, para que possam romper com a visão naturalizada de meio ambiente, de forma que abordem o tema de forma que conduza aos alunos a superação da visão "reducionista" que, muitas vezes, predomina.

Quanto à presença da temática ambiental nos livros que os alunos possuem acesso, a maioria $(60 \%)$ afirmou que esta está bastante presente nas obras. No trabalho desenvolvido por Malafaia e Rodrigues (2009) foi constatado que a maioria dos alunos da EJA tem acesso aos livros que abordam a temática ambiental. Porém, a superficialidade da temática ambiental em livros utilizados nas escolas foi constatada por Fonseca (2007) e Marpica e Logarezzi (2008).

Os assuntos de cunho ambiental muitas vezes são tratados de forma secundária nos livros, ficando reclusos a espaços de pouco destaques, como em box informativos e leituras auxiliares (FONSECA, 2007). Além disso, as temáticas ambientais ligadas aos valores éticos e estéticos e a proposta de participação política, são elementos que estão ausentes em livros didáticos (MARPICA; LOGAREZZI, 2008), comprometendo o despertar de uma educação para a cidadania, como a participação ambiental e a construção de uma visão "abrangente". Esta situação se torna mais grave ainda, na medida em que muitos professores utilizam livros didáticos deficitários como instrumento do processo ensinoaprendizagem, onde há o predomínio, quase sempre, da visão preservacionista e desatualizada do meio ambiente.

Outro aspecto investigado foi a opinião dos alunos sobre os assuntos ambientais, onde todos consideraram que os temas relacionados ao meio ambiente são importantes.

O desenvolvimento de trabalhos que envolvam a temática ambiental junto aos educandos da EJA pesquisados é algo extremamente propício, uma vez que esses demonstram interesse pelo tema. Alguns estudos destacam que a EJA é uma ambiente propício para o desenvolvimento de atividades de educação ambiental, tais como Franco e Satt (2007), Curvello e Latini (2007) e Freitas et al. (2009). No entanto, o ensino de jovens e adultos apresenta características peculiares que devem ser consideradas no momento de qualquer prática educativa. Dentre as peculiaridades está a de ser um grupo muito heterogêneo, onde cada aluno deve ser considerado um ser único, dotado de características cognitivas particulares e rico em história.

Os educadores, nesse contexto, devem sempre que possível vincular os conteúdos com a realidade do aluno da EJA, para que assim, seja possível perceber que estes fazem parte do meio no qual estão inseridos (FREITAS et al., 2009). Isto se justifica, pois, cada aluno traz conhecimentos que devem considerados durante o fazer pedagógico, principalmente com o intuito de ampliar as concepções ambientais que trazem consigo. Para Franco e Satt (2007) isto permite que os alunos da EJA compreendam e modifiquem a realidade ambiental da qual fazem parte.

Além de as práticas de educação ambiental da EJA considerarem as especificidades de cada aluno, estas devem também ser realizadas por meio de metodologias que permitam os alunos se perceberem como componente do meio ambiente. Assim, a educação ambiental possibilita a formação de uma consciência ambiental crítica e cidadã, fazendo com que os indivíduos da EJA, outrora excluídos da escola, tornem-se iguais na autonomia (FRANCO; SATT, 2007).

Outro aspecto investigado buscou saber se os alunos envolvidos na pesquisa apresentavam atitudes de preservação ao meio ambiente, sendo que todos afirmaram positivamente. Com isto, foi possível perceber que os alunos da EJA em questão procuram tomar atitudes que visam à preservação do meio. Este resultado pode contribuir para as práticas de educação ambiental que por ventura sejam realizadas junto aos alunos. No entanto, não se pode deixar de salientar que estes estudantes trazem 
consigo considerável gama de conhecimentos produzidos durante a vivência, que podem também influenciar na resposta para essa questão.

Em estudo realizado por Castoldi et al. (2009), com alunos do ensino médio, a maioria dos pesquisados afirmou que procuram ter atitudes que preservam o meio ambiente. Dentre as atitudes, as mais citadas foram cuidados com o lixo e a economia de água. Já no trabalho desenvolvido por Santos e Bento (2010) questionando se os alunos da EJA tinham ações que prejudicassem o meio ambiente, a maioria respondeu que não. No entanto, uma parcela considerável dos educandos admitiram que apresentam atitudes que geram danos ambientais, como jogar lixo em locais inadequados, provocar queimadas, desperdiçar água, entre outros, contradizendo-se.

Apesar do resultado satisfatório obtido para esta questão, tem-se que destacar a importância de se realizar a educação ambiental, principalmente por meio de projetos que visem à formação de cidadão crítico e que reflitam sobre a sua função dentro da sociedade. Estes trabalhos devem sempre levar o indivíduo de passivo a ativo na compreensão do meio do qual faz parte (DIAS, 2004), tornando-se reflexivos sobre as atitudes em relação ao meio ambiente.

Por fim, foi investigado o que os alunos consideram como problema ambiental que afeta o meio ambiente. Dentre os levantados, o lixo foi o mais citado (45 vezes), seguido pela poluição em geral (23 vezes) e aquecimento global (12 vezes) (Figura 3).

Alguns dos problemas ambientais mencionados pelos alunos são de caráter global, como o aquecimento global, a destruição da camada de ozônio e o desmatamento. É comum, quando se fala em impactos ambientais, a percepção daquilo que não está acontecendo imediatamente ao redor (OENNING; CARNIATTO, 2009). Provavelmente, a citação destes problemas pode estar relacionada à repercussão na mídia, pois atualmente é muito comum se ver debates e discussões sobre os mesmos nos diversos meios de comunicação. Contribui ainda para esta afirmação, o fato de a mídia ser o segundo meio pelo qual os alunos da EJA em questão se informam sobre o meio ambiente e assuntos relacionados.

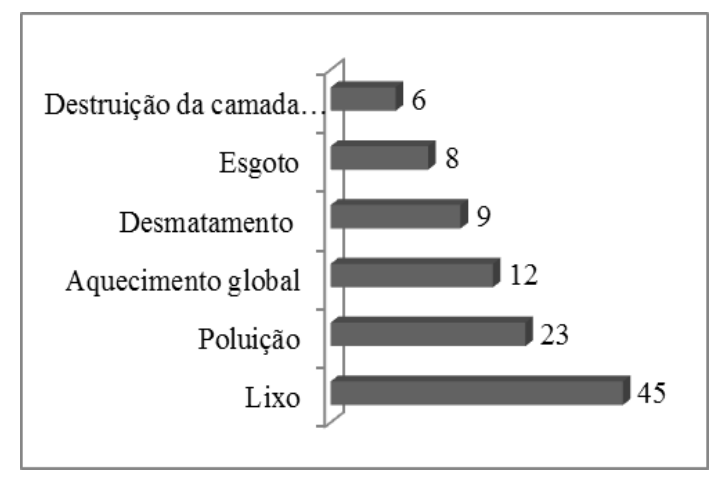

Figura 3 - Problemas ambientais que afetam o meio citado pelos alunos da EJA municipal de Araranguá (SC).

Porém, alguns problemas regionais ou locais também foram citados, como o esgoto, que está relacionado com o saneamento básico, e a produção excessiva de lixo, apontando para a fragilidade das políticas públicas municipais no tocante a estas questões.

Estudos similares, como os realizados por Oenning e Carniatto (2009), Castoldi et al. (2009) e Malafaia e Rodrigues (2009), destacam que os alunos têm capacidade de identificar os principais problemas ambientais. Sendo que dentre dos mais comumente citados estão o lixo, o desmatamento, as queimadas (OENNING; CARNIATTO, 2009; CASTOLDI et al., 2009; MALAFAIA; RODRIGUES, 2009), o aquecimento global (CASTOLDI et al., 2009; MALAFAIA; RODRIGUES, 2009), a poluição em geral (OENNING; CARNIATTO, 2009; CASTOLDI et al., 2009), a poluição do ar (MALAFAIA; RODRIGUES, 2009) e o efeito estufa (CASTOLDI et al., 2009).

Os resultados dos três estudos acima citados corroboram com os encontrados na presente pesquisa, levando a concluir que os alunos da EJA são capazes de citar os principais problemas ambientais relacionados ao contexto social, regional e local. A indicação, por exemplo, do lixo como o problema ambiental mais preocupante, pode ser creditado ao fato deste ser presente no cotidiano dos alunos. 
No entanto, na maioria das vezes, apesar de saberem citar os problemas ambientais, os indivíduos geralmente não compreendem as origens e as consequências. Isto ocorre, pelo fato de não haver criticidade sobre o assunto, não reconhecendo os impactos ambientais e sociais as quais estão submetidos, indicando para o desenvolvimento de educação ambiental que promova a reflexão sobre as relações entre a problemática ambiental e as decisões político-econômicas.

\section{Considerações finais}

A percepção ambiental evidenciada pelos alunos da EJA investigados reflete as experiências pessoais de cada um, pois as respostas trazem a tona atos e situações vivenciadas em sociedade.

Por meio dos resultados do presente estudo foi possível perceber que é extremamente importante o desenvolvimento de práticas de educação ambiental junto aos alunos, para que seja possível superar a visão "reducionista" predominante. As referidas práticas devem permitir que os estudantes adquiram consciência ambiental, ficando clara a importância do meio ambiente, assim como a responsabilidade da sociedade com a conservação e preservação ambiental em busca do desenvolvimento sustentável.

O fato de a pesquisa constatar ser a escola a maior responsável pela aquisição de informações e conhecimentos sobre o meio ambiente reforça a importância e a necessidade de trabalhar a educação ambiental neste espaço de forma crítica, que leve a emancipação e transformação dos envolvidos. Isto deve ocorrer tomando como subsídio a percepção ambiental dos alunos, fazendo-os refletir sobre os aspectos socioeconômicos, éticos e políticos, permitindo encaminhá-los para uma visão abrangente e crítica de meio ambiente.

\section{Referências}

ANDRÉ, M.E.D.A. Estudo de caso em pesquisa e avaliação educacional. Brasília: Liber Livro Editora, 2005.

BEZERRA, T.M.O; GONÇALVEZ, A.A.C. Concepções de meio ambiente e educação ambiental por professores da Escola Agrotécnica Federal de Vitória de Santo Antão - PE. Revista Biotemas, v.20, n.3, 2007.

; Feliciano, A.L.P.; Alves, A.G.C. Percepção ambiental de alunos e professores do entorno da Estação Ecológica de Caetés - Região Metropolitana do Recife-PE. Biotemas, v.21, n.1, 2008.

BRASIL. Lei no 9.795, de 27 de abril de 1999. Dispõe sobre a educação ambiental, institui a Política Nacional de Educação Ambiental e dá outras providências. Diário Oficial [da] República Federativa do Brasil, Poder Executivo, Brasília, DF, 28 abr. 1999.

BRÜGGER, P. Educação ou adestramento ambiental? 3. ed. Chapecó: Argos, 2004.

CARVALHO, I. C. M. Educação ambiental: a formação do sujeito ecológico. 3. ed. São Paulo: Cortez, 2008.

CASTOLDI, R.; BERNARDI, R.; POLINARSKI, C.A. Percepção dos problemas ambientais por alunos do ensino médio. Revista Brasileira de Ciência, Tecnologia e Sociedade, v.1, n.1, 2009.

CERVO, A. L.; BERVIAN, P. A.; SILVA, R. Metodologia científica. 6. ed. São Paulo: Prentice Hall, 2007. 
COSTA, A.P.B.; PAIVA, M. S. D.; FILGUEIRA, J.M. A inserção da educação ambiental na prática pedagógica: uma análise segundo a visão dos alunos dos cursos técnicos integrados do CEFET-RN. HOLOS, 22: 62-73, 2006.

DIAS, G.F. Educação Ambiental: princípios e práticas. 9.ed. São Paulo: Gaia, 2004.

FAGIONNATO, S. Percepção ambiental. 2004. Disponível em: Disponível em: $<$ http://sc.usp.br/cdcc/texto_texto.php>. Acesso em 22 de julho de 2012.

FONSECA, M.J.C.F. A biodiversidade e o desenvolvimento sustentável nas escolas do ensino médio de Belém (PA), Brasil. Educação e Pesquisa, v. 33, n.1, 2007.

FRANCO, J.B.; SATT, J.A.O. A educação ambiental encontrando a educação de jovens e adultos nos diferentes espaços educativos. Revej@ - Revista de Educação de Jovens e Adultos, v.1, p.1-8, 2007.

FRAZÃO, J. O.; SILVA, J.M.; CASTRO, C.S.S. Percepção ambiental de alunos e professores na preservação das tartarugas marinhas na praia de Pipa - RN. Revista Eletrônica do Mestrado em Educação Ambiental, v. 24, janeiro a julho de 2010.

FREITAS, A.C.S.; SANTOS, J.E.O.; BARRETO, L.V. Educação Ambiental no Ensino de Jovens e Adultos. Centro Científico Conhecer - Enciclopédia Biosfera, Goiânia, v.5, n.8, 2009.

GIL, A.C. Como elaborar projetos de pesquisa. 5 ed. São Paulo: Atlas, 2008.

HAMMES, V.S. Percepção Ambiental. In: Hammes, Valeria Sucena. Proposta metodológica da macroevolução. São Paulo: Globo, 2004.

MALAFAIA, G.; RODRIGUES, A.S.L. Percepção ambiental de jovens e adultos de uma escola municipal de ensino fundamental. Revista brasileira de Biociências, Porto Alegre, v. 7, n. 3, p. 266274, jul./set. 2009.

MARPICA, N.S.; LOGAREZZI, A.J.M. As "áreas de silêncio" das questões ambientais em livros didáticos de diferentes disciplinas. Revista Ambiente e Educação, v. 13, n. 1, p. 35-92, 2008.

MARQUES, L.M.; CARNIELLO, M.A.; GUARIM NETO, G. A percepção ambiental como papel fundamental na realização de pesquisa em educação ambiental. Travessias, n.10, 2009.

MOLIN, R.F.; PASQUALI, E.A.; VALDUGA, A.T. Concepções de meio ambiente formulados por estudantes de diferentes níveis de ensino. In: CONGRESSO DE ECOLOGIA DO BRASIL, 8, 2007, Caxambu. Anais... Caxambu (MG), p. 1-2, 2007.

OENNING, V.; CARNIATTO, I. Percepção ambiental de alunos atingidos por barragem em relação a problemas ambientais. Revista Eletrônica do Mestrado Educação Ambiental, v. 23, julho a dezembro de 2009.

REIGOTA, M. Meio ambiente e representação social. São Paulo: Cortez, 2010.

RODRIGUES, A.S.L.; BÁRBARA, V.F.; MALAFAIA, G. Análise das percepções ambientais e dos conhecimentos de alguns conceitos referentes às nascentes de rios revelados por jovens e adultos de uma escola no município de Ouro Preto, MG. Revista Brasileira de Biociências, v. 8, n. 4, p. 355-361, out./dez. 2010.

SANTOS, A.A.M.; BENTO, J.S. A percepção ambiental dos professores e alunos da Educação de Jovens e Adultos. Revista de Ciência, Tecnologia e Humanidades do IFPE, v.4, n.1, 2012. 
SATO, M.; SANTOS, J.E. Tendências nas pesquisas em educação ambiental. In: NOAL, F.O.; BARCELOS, V.H.L. (Orgs.). Educação ambiental e cidadania: cenários brasileiros. Santa Cruz do Sul: EDUNISC, 2003. p. 253-283.

SAUVÉ, L. Educação Ambiental: possibilidades e limitações. Educação e pesquisa, v.31, n.2, p.317322, maio/ago., 2005.

SILVA, M.M.P.; LEITE, V.D. Estratégias para Realização de Educação Ambiental em Escolas do Ensino Fundamental. Rev. eletrônica Mestrado em Educação Ambiental, v. 20, janeiro a junho de 2008.

SILVA, A.D.V.; MENDONÇA, A.W.; MARCOMIN, F.E.; MAZZUCO, K.T.M.; BECKER, R.R. Percepção ambiental como ferramenta para processos de educação ambiental na universidade. Revista Eletrônica Mestrado em Educação Ambiental, v.27, jul./dez., 2011.

SOUZA, L.M.; TRUGILLO, E.A. Percepção ambiental: contextos e possibilidades no cotidiano dos alunos da educação de jovens e adultos. Revista Eventos Pedagógicos, v.3, n.2, p. 152 - 160, Maio - Jul. 2012

SULAIMAN, S.N. Educação ambiental, sustentabilidade e ciência: o papel da mídia na difusão de conhecimentos científicos. Ciência \& Educação, v.17, n.3, p.645-662, 2011.

TAMAIO, I. Mediação do professor na construção do conceito de natureza: uma experiência de Educação Ambiental na Serra da Cantareira e Favela do Flamengo/São Paulo. 152f. 2000. Dissertação (Mestrado em Geociências) - Universidade de Campinas, Campinas, 2000.

YIN, R.K. Estudo de caso: planejamento e métodos. 3 ed. Porto Alegre: Bookman, 2005. 